\title{
Variation in reproductive status of Antarctic krill swarms; evidence for a size-related sorting mechanism?
}

\author{
J. L. Watkins ${ }^{1}$, F. Buchholz ${ }^{2}$, J. Priddle ${ }^{1}$, D. J. Morris ${ }^{3}$, C. Ricketts ${ }^{4}$ \\ ${ }^{1}$ British Antarctic Survey, Natural Environment Research Council, High Cross, Madingley Road, Cambridge CB3 0ET, UK \\ ${ }^{2}$ Institut für Meereskunde an der Universität Kiel, Düsternbrooker Weg 20, W-2300 Kiel, Germany \\ ${ }^{3}$ Metocean Consultancy Ltd., Hamilton House, Kings Road, Haslemere, Surrey GU27 2QA, UK \\ ${ }^{4}$ Department of Mathematics and Statistics, Plymouth Polytechnic, Drake Circus, Plymouth PL4 8AA, UK
}

\begin{abstract}
Length, sex and maturity stage of Antarctic krill Euphausia superba Dana occurring in discrete swarms were measured. Over a $14 \mathrm{~d}$ period 38 swarms were sampled in a small area southwest of Elephant Island, South Shetland Islands. Analysis indicated that the composition of the swarms in terms of the sex ratio and maturity stage was very variable. Swarms ranged from equal mixtures of male and female krill to nearly all one sex; furthermore krill of similar maturity frequently occurred together. The mean length of each maturity stage also varied between swarms; in some swarms the size of each maturity stage was bigger than average while in others each stage was smaller than average. The range of krill sizes in a swarm was often restricted, indicative of some type of size sorting. However size sorting alone could not account for the observed variation in sex ratio and maturity stage and it is likely that in addition, differential growth and active behavioural responses contribute to the observed variation.
\end{abstract}

\section{INTRODUCTION}

The swarming behaviour of Antarctic krill Euphausia superba is a feature of its biology that makes this central species in the food web of the Southern Ocean of particular interest both scientifically (see reviews by Mauchline 1980, Murphy et al. 1988, Miller \& Hampton 1989) and commercially (Eddie 1977). Krill are usually found in dense aggregations which have been classified as patches, shoals, swarms or schools according to the density of individuals and the physical characteristics of the aggregation (Mauchline 1980, Kalinowski \& Witek 1985). In spite of the obvious importance of swarming to understanding the biology of krill relatively little has been published on the variation in composition of individual swarms or schools of krill, with the exception of studies on surface swarms of E. superba (e.g. Marr 1962) and on other euphausiids (Endo 1984, Nicol 1984, O'Brien 1988). Such observations have either been made by divers (Hamner et al. 1983) or on samples taken from aimed net hauls (Quetin \& Ross 1984, Watkins et al. 1986). Recent studies have shown that the composition of adjacent krill swarms may be very different (Morris \& Watkins 1986, Watkins 1986, Watkins et al. 1986) and these differences may be expressed through a wide range of characteristics such as mean length, sex ratio and stages in the moult cycle of the krill in the swarms. In addition Ricketts et al. (1992) have shown that adjacent swarms may be quite different in terms of characteristics measured acoustically such as depth, horizontal extent or cross-sectional area and, furthermore, that swarms with particular biological characteristics cannot be differentiated acoustically.

Samples from individual swarms have indicated that the size range of krill in swarms may be restricted in comparison to the local population (Marr 1962, Hamner 1984, Watkins 1986). Such observations have given rise to proposals for sorting mechanisms based on differential swimming or sinking rates (Mauchline 1980, Kils 1981). 
In this paper we investigate the composition of swarms in terms of the maturity stage and size of the animals in them. In particular we consider the size ranges of krill in different maturity stages in each swarm and the evidence for size-related or other types of swarm sorting mechanism. We also assess the implications of these observations for the reproductive success of Euphausia superba.

\section{METHODS}

Sampling. The 38 Euphausia superba swarms analysed in this study were sampled with a large Longhurst Hardy plankton recorder (LLHPR; Bone 1986) during a $14 \mathrm{~d}$ period in February and March 1985 from an area ca $50 \mathrm{~km}$ square between Elephant Island and King George Island (Fig. 1). Full details of sample collection are given in Watkins et al. (1986) with additional details of acoustic detection and characterization in Ricketts et al. (1992). Within each LLHPR haul contiguous 1 min catches containing krill were pooled for analysis and from each set of pooled catches a random sample of $100 \mathrm{krill}$ were frozen. Nine biological characteristics were measured on the frozen krill (full details in Morris et al. 1988). Here we analyse data collected on total length (anterior edge of eye to tip of telson) and sexual maturity stage (determined using the key of Makarov
\& Deny 1981). Codings for sexual maturity stage (Table 1) are the same as those used by Morris et al. (1988).

Statistical analysis. The association of adult and subadult maturity stages in each swarm was assessed by calculating the correlation coefficients between the proportions of these stages in the 38 swarms using the statistical package MINITAB (Anonymous 1988). Correlations between maturity stages of the same sex were made on the actual numbers in each maturity stage. In contrast, correlations between male and female maturity stages were calculated using the number of each maturity stage as a percentage of the total number of that sex in the swarm because equal numbers of male and female krill were not found in all swarms.

For more extensive analyses utilizing the individual values of the $3409 \mathrm{krill}$ in the complete data set the GENSTAT statistical package (Payne et al. 1987) was used. The effects of swarm and maturity stage on variation in krill length were investigated with analyses of variance. However, the effects of swarm and maturity stage cannot be separated completely (variables are non-orthogonal) and so the order in which the terms were fitted was reversed to explore the seriousness of this problem. Swarms in which the size of the maturity stages differed from the general pattern (i.e. made a large contribution to the maturity stage-swarm interaction mean square) were identi-

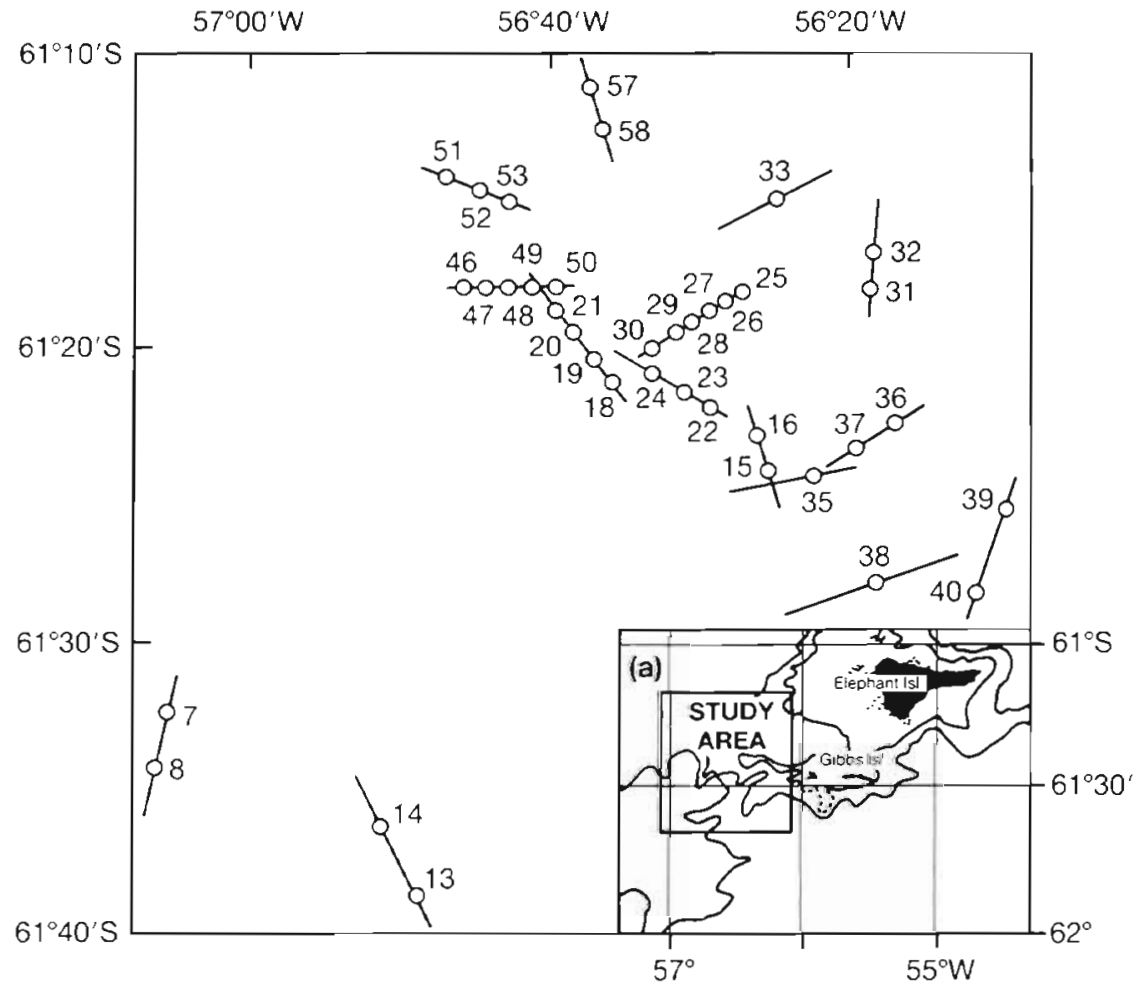

Fig. 1 Euphausia superba. Location of haul tracks and the 38 swarms (0) sampled in the study area. Inset (a): overall location of study area 
Table 1 Euphausia superba. Codes and definitions for sex and maturity stages

\begin{tabular}{|c|c|c|}
\hline Code & Definition & Characteristics \\
\hline J & Juvenile & $\begin{array}{l}\text { No visible secondary sexual } \\
\text { characteristics }\end{array}$ \\
\hline MS1 & Male subadult 1 & Small single lobed petasma \\
\hline MS2 & Male subadult 2 & Petasma has 2 lobes but no wing \\
\hline MS3 & Male subadult 3 & $\begin{array}{l}\text { Petasma has wing but not fully } \\
\text { developed }\end{array}$ \\
\hline MA1 & Male adult 1 & $\begin{array}{l}\text { Fully developed petasma, red } \\
\text { ejaculatory ducts but no fully } \\
\text { formed spermatophores }\end{array}$ \\
\hline MA2 & Male adult 2 & $\begin{array}{l}\text { Fully formed spermatophores } \\
\text { easily ejected }\end{array}$ \\
\hline FS & Female subadult & $\begin{array}{l}\text { Thelycum not fully developed } \\
\text { or coloured }\end{array}$ \\
\hline FA1 & Female adult 1 & $\begin{array}{l}\text { Red, fully developed thelycum } \\
\text { but no attached spermatophores }\end{array}$ \\
\hline FA2 & Female adult 2 & $\begin{array}{l}\text { Attached spermatophores but } \\
\text { ovary does not fill thoracic cavity }\end{array}$ \\
\hline FA3 & Female adult 3 & $\begin{array}{l}\text { Ovary fills thoracic cavity and } \\
\text { extends into first } 2 \text { abdominal } \\
\text { segments but body is not swollen }\end{array}$ \\
\hline FA4 & Female adult 4 & $\begin{array}{l}\text { Gravid female with heavily } \\
\text { swollen thorax and front of } \\
\text { abdomen filled with visible ovary }\end{array}$ \\
\hline FA5 & Female adult 5 & $\begin{array}{l}\text { Spent female with swollen body } \\
\text { but ovary occupying only a small } \\
\text { portion of empty cavity }\end{array}$ \\
\hline
\end{tabular}

fied by the coefficients and their associated $t$-values as given by GENSTAT. In some of those swarms initially identified as having a significant contribution not all maturity stages were present. Therefore to remove this potential source of error a subset of the data using male krill from those swarms that contained all the male maturity stages was then used for a further analysis of variance. In both analyses the 2 groups of mature males (MA1 and MA2) were pooled because the only difference between these stages is the absence or presence of ejectable spermatophores. Adult male krill may not have spermatophores (MA1) either because they have not yet developed or because they have just been ejected and so there seemed to be no reason for expecting the stages MA1 and MA2 to have different mean sizes.

In order to see whether the size ranges (difference between largest and smallest krill) observed in the swarms could have occurred by chance, they were compared with the sizes ranges occurring in a set of artificial swarms that were generated by the random assignment of individuals from the total population to the 38 swarms (see Watkins et al. 1990 for more details).

\section{RESULTS}

\section{Swarm composition}

It has been shown in previous papers (Watkins et al. 1986, Ricketts et al. 1992) that the composition of swarms with respect to sex was highly variable: compare for instance Swarms 7 and 8 or Swarms 25 to 30 (Table 2). Male and female krill were found in all swarms but the relative proportions varied greatly (from 19 to $98 \%$ male in individual swarms while $53 \%$ of overall population were male). Similarly there was considerable variation in proportion of adults in the swarms (from 37 to $100 \%$, while $83 \%$ of the overall population were adults). However only 14 swarms contained a large proportion of subadults (more than 10\%) while the proportion of adults was greater than $95 \%$ in 19 swarms (Table 2).

Here we study in detail the great variation in the relative frequency of occurrence of the individual maturity stages within the swarms (Table 2). The 2 adult male stages, without and with spermatophores (MA1 and MA2 respectively), were the only maturity stages found in all the swarms. While adult females were recorded in all swarms there was no single female maturity stage that occurred in every swarm. There was also variation in the number of maturity stages in a swarm; some swarms (27 and 39) contained nearly every maturity stage while in others the number of stages present was very limited, for instance in Swarm 58 nearly all the krill were either MA1 or MA2.

Certain maturity stages of one sex often occurred with certain stages of the other sex in all swarms (Table 3). For instance, the numbers of subadult male, subadult female and relatively immature female krill (i.e. those without attached spermatophores, FA1, and those with attached spermatophores but with an undeveloped ovary, FA2) were correlated significantly (Table 3). In a similar way, the occurrence of mature males (MA2) was correlated with the occurrence of mature females (FA3, females with ovary filling body cavity), although there was no positive correlation with any other female stage. This has obvious implications for maturity stages such as FA2 and FA4 (gravid krill) which are also actively moulting and thus requiring regular spermatophore attachment to ensure egg fertilization (Buchholz et al. unpubl.). In contrast, the occurrence of mature adult males was negatively correlated with subadult and relatively immature adult females (FA1 and FA2).

When comparing different maturity stages of the same sex, individuals of similar maturity occurred together. The numbers of first, second and third stage subadult male krill (MS1, MS2, MS3, respectively) in a swarm were correlated (Table 4). Amongst the females, there was a positive correlation between the 
Table 2. Euphausia superba. Maturity-stage composition (\%) of 38 swarms and range between maximum and minimum sizes of krill in each swarm plus number of krill in each swarm sample. Male: percentage of male krilli subadult: total percentage of subadults; adult: total percentage of adults. Swarms that occurred in the same haul are grouped together. Vertical bars: comparisons of swarms within hauls with respect to sex ( $\%$ male), overall maturity (\% adult and \% subadult) and detailed maturity stages for each sex (MS1, MS2 etc.) by means of chi ${ }^{2}$ are not significant ( $\left.p>0.01\right)$. Slight discrepancies $(1 \%)$ obtained when adding $\%$ of krill in each maturity stage may occur due to rounding to nearest whole number throughout table

\begin{tabular}{|c|c|c|c|c|c|c|c|c|c|c|c|c|c|c|c|c|}
\hline \multirow[t]{2}{*}{ Swarm } & \multicolumn{14}{|c|}{ Percentage of krill in each stage } & \multirow{2}{*}{$\begin{array}{c}\text { Size } \\
\text { range } \\
(\mathrm{mm})\end{array}$} & \multirow{2}{*}{$\begin{array}{c}\text { Number } \\
\text { of } \\
\text { krill }\end{array}$} \\
\hline & Male & $\begin{array}{l}\text { Sub- } \\
\text { adult }\end{array}$ & Adult & MS1 & $\mathrm{MS} 2$ & MS3 & MA1 & MA2 & FS & FA 1 & FA2 & FA3 & FA4 & FA5 & & \\
\hline 7 & 51 & 58 & 37 & 18 & 12 & 7 & 8 & 5 & 21 & 7 & 14 & 0 & 2 & 0 & 20 & 184 \\
\hline 8 & 97 & 6 & 94 & 0 & 3 & 3 & 15 & 76 & 0 & 0 & 0 & 0 & 0 & 0 & 11 & 35 \\
\hline 13 & 42 & 1 & 991 & 0 & 1 & 0 & 8 & 33 & 0 & 1 & 7 & 19 & 31 & 0 & 13 & 419 \\
\hline 14 & 86 & 6 & 931 & 2 & 2 & 0 & 16 & 66 & 2 & 0 & 7 & 2 & 2 & 01 & 12 & 48 \\
\hline 15 & 64 & 38 & 601 & 5 & 15 & 10 & 21 & 13 & 8 & 8 & 15 & 1 & 2 & 0 & 17 & 70 \\
\hline 16 & 38 & 30 & 651 & 8 & 8 & 5 & 11 & 6 & 9 & 9 & 32 & 3 & 2 & 21 & 17 & 533 \\
\hline 18 & 86 & 1 & 99 & 0 & 1 & 0 & 12 & 73 & 0 & 4 & 5 & 4 & 1 & 0 & 14 & 81 \\
\hline 19 & 87 & 1 & 99 & 0 & 1 & 0 & 21 & 65 & 0 & 1 & 4 & 7 & 0 & 1 & 12 & 120 \\
\hline 20 & 38 & 0 & 100 & 0 & 0 & 0 & 5 & 33 & 0 & 0 & 12 & 26 & 15 & 8 & 12 & 67 \\
\hline 21 & 67 & 28 & 71 & 12 & 6 & 4 & 11 & 34 & 6 & 4 & 4 & 6 & 11 & 1 & 18 & 758 \\
\hline 22 & 45 & 28 & 72 & 6 & 8 & 12 & 5 & 14 & 2 & 20 & 28 & 1 & 3 & 0 & 17 & 203 \\
\hline 23 & 43 & 45 & 54 & 7 & 18 & 10 & 4 & 4 & 10 & 12 & 18 & 10 & 6 & 0 & 19 & 553 \\
\hline 24 & 58 & 18 & 82 & 6 & 8 & 4 & 15 & 24 & 0 & 3 & 7 & 16 & 16 & 0 & 15 & 796 \\
\hline 25 & 73 & 12 & 87 & 3 & 7 & 2 & 22 & 39 & 0 & 4 & 6 & 8 & 3 & 5 & 15 & 243 \\
\hline 26 & 80 & 9 & 90 & 2 & 5 & 2 & 12 & 59 & 0 & 2 & 2 & 4 & 8 & 0 & 14 & 186 \\
\hline 27 & 66 & 1.5 & 85 & 2 & 7 & 5 & 13 & 39 & 1 & 4 & 5 & 13 & 9 & 2 & 15 & 293 \\
\hline 28 & 62 & 22 & 77 & 6 & 10 & 5 & 13 & 28 & 1 & 7 & 5 & 10 & 14 & 0 & 21 & 739 \\
\hline 29 & 19 & 4 & 96 & 0 & 1 & 3 & 5 & 10 & 0 & 0 & 5 & 30 & 45 & 1 & 14 & 436 \\
\hline 30 & 75 & 2 & 98 & 0 & 1 & 1 & 18 & 55 & 0 & 0 & 5 & 12 & 8 & 0 & 14 & 307 \\
\hline 31 & 23 & 5 & 95 & 0 & 5 & 0 & 5 & 13 & 0 & 1 & 0 & 21 & 52 & 3 & 16 & 435 \\
\hline 32 & 77 & 34 & 66 & 9 & 10 & 15 & 22 & 21 & 0 & 5 & 6 & 5 & 5 & 2 & 12 & 289 \\
\hline 33 & 36 & 1 & 99 & 0 & 1 & 0 & 14 & 21 & 0 & 0 & 1 & 15 & 41 & 7 & 17 & 143 \\
\hline 35 & 57 & 13 & 87 & 0 & 6 & 5 & 6 & 40 & 2 & 2 & 3 & 7 & 27 & 2 & 18 & 155 \\
\hline 36 & 33 & 1 & 99 & 1 & 0 & 0 & 7 & 25 & 0 & 0 & 0 & 21 & 45 & 0 & 15 & 147 \\
\hline 37 & 25 & 7 & 93 & 1 & 4 & 0 & 5 & 16 & 2 & 0 & 6 & 23 & 39 & 4 & 19 & 89 \\
\hline 38 & 27 & 1 & 99 & 0 & 1 & 0 & 7 & 19 & 0 & 1 & 4 & 21 & 37 & 2 & 14 & 118 \\
\hline 39 & 44 & 47 & 48 & 18 & 14 & 5 & 4 & 3 & 10 & 5 & 26 & 8 & 1 & $1 \mid$ & 19 & 146 \\
\hline 40 & 53 & 45 & 49 & 6 & 9 & 15 & 4 & 17 & 15 & 1.1 & 13 & 4 & 0 & 0 & 30 & 51 \\
\hline 46 & 62 & 1 & 99 & 0 & 1 & 0 & 12 & 49 & 0 & 2 & 13 & 14 & 2 & 6 & 15 & 138 \\
\hline 47 & 53 & 0 & 100 & 0 & 0 & 0 & 9 & 44 & 0 & 0 & 10 & 13 & 13 & 3 & 15 & 80 \\
\hline 48 & 40 & 2 & 98 & 0 & 0 & 2 & 9 & 29 & 0 & 1 & 14 & 30 & 14 & 1 & 13 & 308 \\
\hline 49 & 44 & 8 & 9.1 & 0 & 3 & 4 & 11 & 25 & 1 & 2 & 10 & 18 & 25 & 0 & 26 & 492 \\
\hline 50 & 57 & 5 & 95 & 2 & 2 & 1 & 8 & 44. & 0 & 1 & 6 & 14 & 22 & 0 & 16 & 904 \\
\hline 51 & 40 & 0 & 100 & 0 & 0 & 0 & 8 & 32 & 0 & 2 & 15 & 18 & 6 & 9 & 17 & 76 \\
\hline 52 & 72 & 2 & 98 & 0 & 2 & 0 & 23 & 47 & 0 & 1 & 11 & 11 & 1 & 1 & 13 & 109 \\
\hline 53 & 59 & 1 & 98 & 0 & 0 & 1 & 8 & 50 & 0 & 1 & 10 & 12 & 1 & 8 & 25 & 86 \\
\hline 57 & 74 & 0 & 100 & 0 & 0 & 0 & 14 & 60 & 0 & 0 & 8 & 7 & 6 & 5 & 11 & 103 \\
\hline 58 & 98 & 1 & 99 & 0 & 0 & 1 & 20 & 77 & 0 & 0 & 1 & 1 & 0 & 0 & 13 & 104 \\
\hline
\end{tabular}


Table 3. Euphausia superba. Matrix of correlations between the proportion of krill in each male maturity stage and the proportion of krill in each female maturity stage. Data used for correlations taken from Table 1 To remove biases due to differing numbers of males and females in each swarm, data were converted to percentage of the total number of male or female krill respectively in each swarm. For each maturity stage pairing, swarms that did not contain either stage were excluded from the analysis

\begin{tabular}{|llllll|}
\hline & MS1 & \multicolumn{1}{l}{ MS2 } & \multicolumn{1}{c}{ MS3 } & MA1 & MA2 \\
\hline FS & $0.66^{*}$ & $0.58 \cdots$ & $0.48 \cdot$ & -0.27 & $-0.69 \cdots$ \\
FA1 & $0.41^{\circ}$ & $0.50 \cdots$ & $0.68 \cdots$ & -0.20 & $-0.63 \cdots$ \\
FA2 & $0.40^{\circ}$ & 0.23 & 0.28 & -0.10 & $-0.36 \cdot$ \\
FA3 & $-0.61 \cdots$ & $-0.55 \cdots$ & $-0.55 \cdots$ & 0.24 & $0.57 \cdots$ \\
FA4 & $-0.41^{*}$ & -0.18 & -0.27 & 0.19 & 0.23 \\
FA5 & -0.24 & -0.24 & -0.22 & -0.05 & 0.25 \\
p p $0.05 ;$ & $\cdots p<0.01$ & $\cdots p<0.001$ & & \\
\hline
\end{tabular}

occurrence of maturity stages FA3 and FA4 while the subadult (FS) and immature adult females (FA1 and FA2) occurred together (Table 4). Thus in general, krill of a similar maturity stage occurred together in a swarm.

Swarms that were sampled in the same haul were both spatially and temporally close, that is, between $100 \mathrm{~m}$ and $5 \mathrm{~km}$ apart and caught within $1 \mathrm{~h}$ of each other. Despite this proximity, these swarms were frequently quite different: compare for instance Swarms 25 to 30 sampled in a single haul $5 \mathrm{~km}$ in length (Table 2). Distances between swarms within a haul were estimated by counting the number of empty catches (each representing around $120 \mathrm{~m}$ ) between samples containing krill. Correlations for the distance

Table 4. Euphausia superba. Correlation matrices for the number of krill in each maturity stage in each swarm. Data used for correlations taken from Table 1 For each maturity stage pairing, swarms that did not contain either stage were excluded from the analysis

\begin{tabular}{|c|c|c|c|c|c|}
\hline & \multicolumn{2}{|r|}{$\begin{array}{l}\text { Males } \\
\text { MS2 }\end{array}$} & MS3 & \multicolumn{2}{|c|}{ MA1 } \\
\hline MS2 & $0.73 \cdots$ & & & \multirow{4}{*}{\multicolumn{2}{|c|}{$0.49^{\circ}$}} \\
\hline MS3 & $0.48^{\cdots}$ & $0.74^{\cdots}$ & & & \\
\hline MA1 & -0.13 & -0.06 & -0.05 & & \\
\hline \multirow[t]{3}{*}{ MA2 } & $-0.53 \cdots$ & $-0.58 \cdot \cdot$ & $-0.49^{\circ}$ & & \\
\hline & \multicolumn{3}{|c|}{ Females } & \multirow[b]{2}{*}{ FA3 } & \multirow[b]{2}{*}{ FA4 } \\
\hline & FS & FA 1 & FA2 & & \\
\hline FA1 & $0.50^{\circ}$ & & & \multirow{5}{*}{$\begin{array}{l}0.70 \cdots \\
0.27\end{array}$} & \multirow[b]{5}{*}{0.01} \\
\hline FA2 & $0.49^{\circ}$ & $0.65 \cdots$ & & & \\
\hline FA3 & $-0.46^{\cdots}$ & $-0.50^{\cdots}$ & -0.23 & & \\
\hline FA4 & $-0.36^{\circ}$ & $-0.42^{\circ}$ & $-0.47 \cdots$ & & \\
\hline FA5 & $-0.44^{\circ}$ & $-0.41^{\circ}$ & -0.03 & & \\
\hline
\end{tabular}

between krill swarms and the difference in proportions of mature krill $(r=0.03$ ) or proportions of male krill $(r=-0.06)$ were insignificant $(n=44 ; r=0.38$ when $\mathrm{p}=0.01)$. Thus swarms only $100 \mathrm{~m}$ apart were quite different (for instance Swarms 31 and 32). In contrast, swarms that were in the same haul but well separated (for instance Swarms 36 and 37 which were about $2 \mathrm{~km}$ apart) or swarms that occurred in different hauls and were thus spatially and temporally even more distinct (e.g. Swarms 7 and 39) were often quite similar.

The relationship between the sex ratio and the proportion of subadults in the swarms was highly variable (Fig. 2). Note, however, that in swarms where most of the krill were one sex (male) there were very few subadult krill (Swarms 8, 18, 19, 58). The relationship between the sex ratio in the swarm and the size of the samples caught in the net was also highly variable (Table 2, Fig. 3). However, again while samples that contained more or less equal proportions of both sexes may have been either large or small, samples that were predominantly one sex tended to be small.

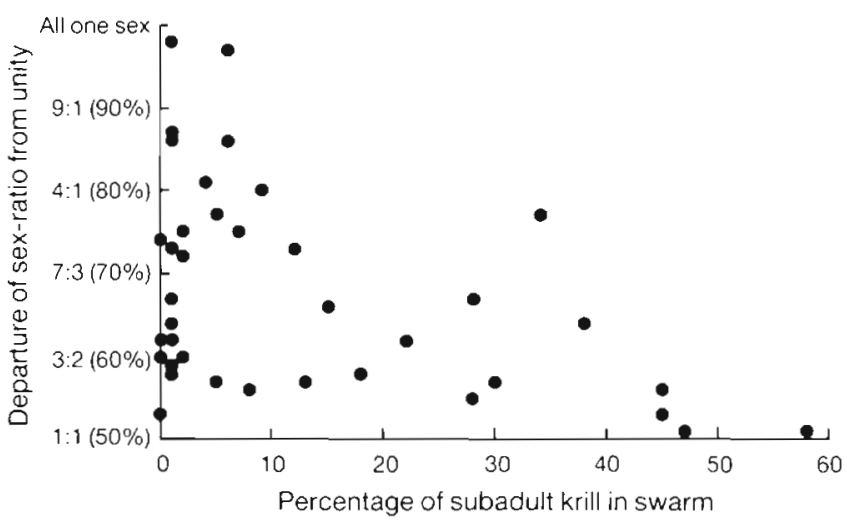

Fig. 2. Euphausia superba. Relationship between sex ratio and proportion of subadult krill in the swarms

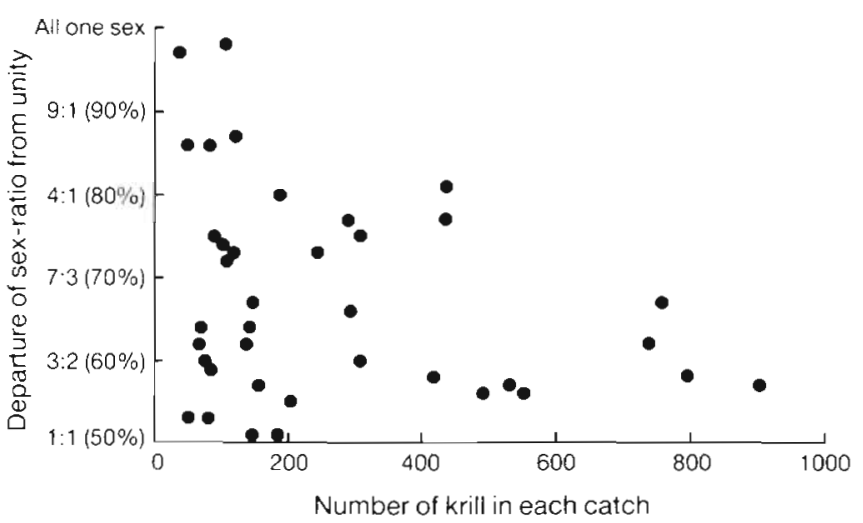

Fig. 3. Euphausia superba. Relationship between sex ratio and number of krill caught in the net in 38 swarms 


\section{Size of maturity stages}

As well as being very variable in terms of the mix of maturity stages, there was also considerable variation in the mean length of the krill in each swarm (righthand column in Table 5). From the ANOVA, 6 or $18 \%$ of the total variation in length can be attributed to differences between swarms (depending on whether term 'swarm' fitted after or before 'maturity stage' in ANOVA). Maturity stage also had a very marked effect on krill length, explaining between 13 and $25 \%$ of the total variation (top row of Table 5).

The mean length of each maturity stage increased with maturity. However, note that the overall mean length of final stage immature males (MS3) was greater than the mean length of male adult krill (MA1)

Table 5. Euphausia superba. Deviation of mean length (mm) for each maturity stage in each swarm from overall mean length for each maturity stage in the local population (top row). Overall mean length for each swarm shown in last column. Asterisks: cells containing less than 5 individuals

\begin{tabular}{|c|c|c|c|c|c|c|c|c|c|c|c|c|}
\hline Pop, mean for stages: & $\begin{array}{l}\text { MS1 } \\
42.8\end{array}$ & $\begin{array}{l}\text { MS2 } \\
46.8\end{array}$ & $\begin{array}{l}\text { MS3 } \\
48.4\end{array}$ & $\begin{array}{l}\text { MA } 1 \\
48.0\end{array}$ & $\begin{array}{l}\text { MA2 } \\
48.5\end{array}$ & $\begin{array}{l}\text { FS } \\
41.1\end{array}$ & $\begin{array}{l}\text { FA.1 } \\
43.7\end{array}$ & $\begin{array}{l}\text { FA2 } \\
46.0\end{array}$ & $\begin{array}{l}\text { FA3 } \\
47.2\end{array}$ & $\begin{array}{l}\text { FA4 } \\
48.8\end{array}$ & $\begin{array}{l}\text { FA5 } \\
48.3\end{array}$ & $\begin{array}{l}\text { All stages } \\
47.5\end{array}$ \\
\hline Swarm number & & & & & & & & & & & & Swarm mean \\
\hline $\begin{array}{l}7 \\
8\end{array}$ & 0.7 & 1.1 & 0.6 & $\begin{array}{r}0.4 \\
-1.2\end{array}$ & $\begin{array}{r}-0.7 \\
1.1\end{array}$ & 1.7 & -2.1 & 2.6 & & " & $\cdot$ & $\begin{array}{l}45.3 \\
48.9\end{array}$ \\
\hline $\begin{array}{l}13 \\
14\end{array}$ & $\cdot$ & $\dot{.}$ & & $\begin{array}{r}-0.4 \\
1.1\end{array}$ & $\begin{array}{r}0.1 \\
-0.2\end{array}$ & $\cdot$ & $\cdot$ & 2.9 & 0.4 & -0.4 & & $\begin{array}{l}48.2 \\
48.0\end{array}$ \\
\hline $\begin{array}{l}15 \\
16\end{array}$ & $\begin{array}{r}4.2 \\
-2.2\end{array}$ & $\begin{array}{r}0.7 \\
-0.8\end{array}$ & 1.3 & $\begin{array}{r}0.6 \\
-0.6\end{array}$ & 0.0 & $\begin{array}{r}1.2 \\
-0.5\end{array}$ & $\begin{array}{r}0.7 \\
-0.2\end{array}$ & $\begin{array}{r}0.6 \\
-0.8\end{array}$ & $\dot{.}$ & $\dot{\cdot}$ & $\cdot$ & $\begin{array}{l}47.2 \\
44.9\end{array}$ \\
\hline $\begin{array}{l}18 \\
19 \\
20 \\
21\end{array}$ & -0.4 & $\begin{array}{c}\cdot \\
-0.4\end{array}$ & . & $\begin{array}{l}-0.6 \\
-1.7 \\
0.5\end{array}$ & $\begin{array}{r}0.5 \\
-1.5 \\
0.4 \\
-0.4\end{array}$ & 0.9 & $\dot{.}$ & $\begin{array}{l}\dot{\cdot} \\
1.5 \\
\cdot\end{array}$ & $\begin{array}{r}\cdot \\
0.1 \\
1.4 \\
-2.4\end{array}$ & $\begin{array}{c}\cdot \\
-0.3 \\
-1.4\end{array}$ & $\begin{array}{l}\cdot \\
3.1\end{array}$ & $\begin{array}{l}48.5 \\
46.7 \\
48.7 \\
46.3\end{array}$ \\
\hline $\begin{array}{l}22 \\
23 \\
24\end{array}$ & $\begin{array}{r}-0.1 \\
-2.2 \\
3.7\end{array}$ & $\begin{array}{r}-1.1 \\
-0.4 \\
1.2\end{array}$ & $\begin{array}{r}-0.4 \\
0.2 \\
\cdot\end{array}$ & $\begin{array}{c}-1.6 \\
0.2\end{array}$ & $\begin{array}{c}-1.2 \\
1.1\end{array}$ & -0.2 & $\begin{array}{r}0.6 \\
-1.3 \\
.\end{array}$ & $\begin{array}{r}-0.3 \\
-0.4 \\
0.5\end{array}$ & $\begin{array}{c}\cdot \\
-1.9 \\
-1.1\end{array}$ & $\begin{array}{c}\cdot \\
-2.7 \\
-2.5\end{array}$ & & $\begin{array}{l}45.6 \\
45.1 \\
47.7\end{array}$ \\
\hline $\begin{array}{l}25 \\
26 \\
27 \\
28 \\
29 \\
30\end{array}$ & $\begin{array}{c}\dot{\cdot} \\
-2.0\end{array}$ & $\begin{array}{r}-1.3 \\
1.6 \\
0.7 \\
-2.8 \\
\cdot \\
\cdot\end{array}$ & $\begin{array}{c}\cdot \\
-1.2 \\
-2.0 \\
\dot{\cdot}\end{array}$ & $\begin{array}{r}0.6 \\
0.9 \\
-0.6 \\
-1.4 \\
2.2 \\
-1.4\end{array}$ & $\begin{array}{r}-0.3 \\
-0.2 \\
0.2 \\
0.3 \\
1.7 \\
-0.2\end{array}$ & $\dot{.}$ & $\begin{array}{c}\cdot \\
\cdot \\
-1.7\end{array}$ & $\begin{array}{r}-0.6 \\
\cdot \\
0.8 \\
-2.6 \\
1.2 \\
0.4\end{array}$ & $\begin{array}{r}-0.5 \\
- \\
-0.8 \\
-2.0 \\
0.6 \\
-0.9\end{array}$ & $\begin{array}{r}0.2 \\
0.7 \\
-0.7 \\
-3.0 \\
0.7 \\
1.7\end{array}$ & $\begin{array}{c}-0.5 \\
. \\
.\end{array}$ & $\begin{array}{l}47.4 \\
48.0 \\
47.4 \\
45.6 \\
49.0 \\
47.8\end{array}$ \\
\hline $\begin{array}{l}31 \\
32\end{array}$ & 2.1 & $\begin{array}{r}5.0 \\
-0.3\end{array}$ & -0.8 & $\begin{array}{l}-0.2 \\
-1.3\end{array}$ & $\begin{array}{r}0.1 \\
-1.4\end{array}$ & & 0.5 & -1.0 & $\begin{array}{r}0.9 \\
-0.2\end{array}$ & $\begin{array}{l}1.4 \\
0.4\end{array}$ & $\dot{r}$ & $\begin{array}{l}49.3 \\
46.6\end{array}$ \\
\hline 33 & & $\cdot$ & & -0.4 & 0.5 & & & " & 0.7 & 0.2 & 0.2 & 48.6 \\
\hline 35 & & 0.4 & -1.0 & 0.5 & 0.9 & $\cdot$ & $\cdot$ & $\cdot$ & -1.5 & -0.6 & $\cdot$ & 48.2 \\
\hline $\begin{array}{l}36 \\
37\end{array}$ & . & . & & $\begin{array}{l}1.6 \\
\cdot\end{array}$ & $\begin{array}{l}1.7 \\
0.0\end{array}$ & $\cdot$ & & -0.8 & $\begin{array}{l}1.7 \\
0.3\end{array}$ & $\begin{array}{r}1.4 \\
-0.3\end{array}$ & $\cdot$ & $\begin{array}{l}49.8 \\
47.6\end{array}$ \\
\hline 38 & & $\cdot$ & & 0.8 & -0.4 & & $\cdot$ & $\cdot$ & 1.1 & -0.1 & $\cdot$ & 48.4 \\
\hline $\begin{array}{l}39 \\
40\end{array}$ & -2.5 & -2.8 & $\begin{array}{r}0.6 \\
-1.0\end{array}$ & $\dot{\cdot}$ & $\begin{array}{c}\cdot \\
-1.3\end{array}$ & $\begin{array}{l}-2.2 \\
-0.6\end{array}$ & $\begin{array}{r}-2.5 \\
0.9\end{array}$ & $\begin{array}{l}-4.0 \\
-1.6\end{array}$ & -3.7 & $\cdot$ & $\cdot$ & $\begin{array}{l}42.2 \\
44.7\end{array}$ \\
\hline $\begin{array}{l}46 \\
47 \\
48 \\
49 \\
50\end{array}$ & . & $\dot{.}$ & $\dot{.}$ & $\begin{array}{l}0.3 \\
1.3 \\
0.5 \\
3.0 \\
3.4\end{array}$ & $\begin{array}{r}-0.4 \\
0.5 \\
-0.5 \\
-0.7 \\
0.3\end{array}$ & $\cdot$ & $\begin{array}{l}\cdot \\
\cdot \\
\cdot\end{array}$ & $\begin{array}{r}-1.1 \\
1.6 \\
-0.7 \\
3.0 \\
1.9\end{array}$ & $\begin{array}{r}-0.9 \\
0.7 \\
-1.5 \\
-0.8 \\
1.3\end{array}$ & \begin{tabular}{r}
\multicolumn{1}{c}{} \\
0.0 \\
0.0 \\
-1.0 \\
0.5
\end{tabular} & $\begin{array}{l}-0.6 \\
.\end{array}$ & $\begin{array}{l}47.5 \\
48.7 \\
47.1 \\
48.0 \\
49.0\end{array}$ \\
\hline $\begin{array}{l}51 . \\
52 \\
53\end{array}$ & & $\cdot$ & . & $\begin{array}{r}-0.6 \\
-0.8 \\
0.3\end{array}$ & $\begin{array}{r}-1.3 \\
0.1 \\
-0.1\end{array}$ & & $\begin{array}{c}\cdot \\
-1.7\end{array}$ & $\begin{array}{r}1.6 \\
-0.4 \\
1.3\end{array}$ & $\begin{array}{r}2.8 \\
-0.6 \\
-\end{array}$ & $\begin{array}{c}4.6 \\
-4.8\end{array}$ & $\begin{array}{l}0.7 \\
0.4\end{array}$ & $\begin{array}{l}48.4 \\
47.6 \\
47.9\end{array}$ \\
\hline $\begin{array}{l}57 \\
58\end{array}$ & & & $\cdot$ & $\begin{array}{l}0.2 \\
0.3\end{array}$ & $\begin{array}{l}0.4 \\
0.4\end{array}$ & & & 2.2 & $\begin{array}{l}2.4 \\
\cdot\end{array}$ & 0.2 & 0.9 & $\begin{array}{l}48.8 \\
48.8\end{array}$ \\
\hline
\end{tabular}


and that gravid females (FA4) were longer than spent females (FA5). In the ANOVA, virtually all the contribution of maturity stage to the total variation could be partitioned into 2 components. The majority of the variation (90\% of total maturity stage variation) was due to a linear trend of increasing length with increasing maturity and a small part $18 \%$ of total maturity stage variation) was due to a quadratic term which represented the frequently observed decrease in length on reaching stages FA5 or MA.

\section{Inter-swarm variation in size of maturity stages}

From the above section and as mentioned briefly by Watkins et al. (1986), we see that because maturity stages vary in length the overall mean length of krill in a swarm depends on the maturity-stage composition of the swarm. In addition, the mean size of each particular maturity stage varied between swarms (Table 5). This is represented in the ANOVA by the interaction term of 'swarm and maturity' which accounted for $8 \%$ of the total sum of squares. Indeed when considering the mean length of each maturity stage in individual swarms there were frequent exceptions to the general pattern observed for the population; for instance MA1 adult males were larger than MA2 adult males in about a third of all swarms, while in Swarms 7,15 and 39 immature males (MS3) were the longest in the swarm. Overall, spent females were shorter than gravid females; however, in 2 of the 4 swarms in which there were at least $5 \mathrm{krill}$ of both stages present, spent females were longer than gravid females. Deviations in the size of a maturity stage in an individual swarm from the population mean size of that stage were as great as $5 \mathrm{~mm}$ ( $\mathrm{SD}=1.44 \mathrm{~mm}$; see for instance Swarm 31 and 53), although the largest deviations occurred when few examples of that maturity stage were found in the swarm. Thus the overall mean length of krill in a swarm was an expression of both the mix of maturity stages and the mean lengths of the maturity stages in that particular swarm.

\section{Effects of variation in composition and size of maturity stages on krill mean length}

The variation in mean length of krill in swarms that were spatially and temporally close was investigated by looking at the inter-swarm variation within individual hauls. There were significant differences between the mean length of krill from swarms in 10 of the 13 hauls tested (no differences were found in the hauls containing Swarms 13 and 14;51,52, and 53 and 57 and 58). Where there were differences in the overall mean length of krill in swarms within a haul, the relative effect of the composition and length of the maturity stages on the differences between the mean length of krill in the swarms was investigated as follows. Differences due to the variation in the length of each maturity stage in different swarms were removed by assigning the population mean length for the appropriate maturity stage to each animal in the swarm. With the effect of between-swarm maturitystage size differences removed, 2 types of swarm became evident. Swarms of the first type showed no significant within-haul differences in their mean length (top of Fig. $4 ; p<0.05$ with exception of 2 hauls
Fig. 4. Euphausia superba. Relative effects of maturity-stage composition and changes in the size of maturity stages on the overall mean length of krill in each swarm. Mean length of krill in swarms that were temporally and spatially close (i.e. in the same haul) shown by thick horizontal bars. Mean length of krill in swarms after effect of inter-swarm differences in maturity stage size removed are shown by thin horizontal bars

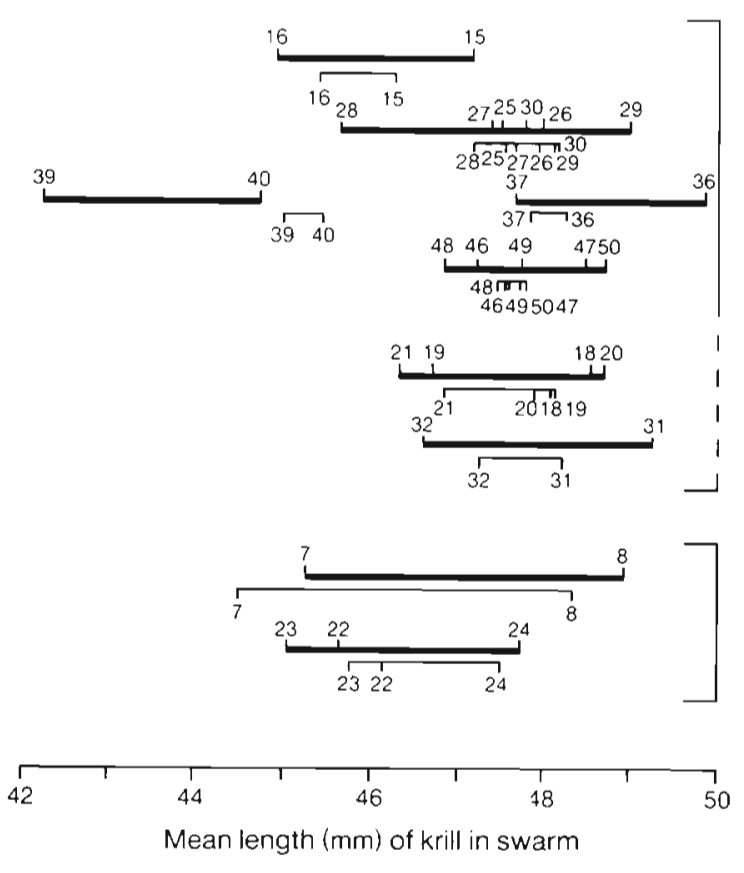

Type 1, hauls where swarm differences are due to differences in size of corresponding maturity stages

Type 2; hauls where swarm differences are due to differing proportions of male and female krill or adult and subadult krill 
linked by dotted line where $0.05>p>0.01$ ). Swarms of the second type remained significantly different (bottom of Fig. 4; $p<0.01$ ). Therefore, in the original data set a significant part of the overall difference in the mean length of krill in, for example, Swarms 15 and 16 or Swarms 36 and 37 (Type 1) was caused by differences between the swarms in terms of the size of the krill in each maturity stage. In contrast, the differences in mean length of krill in Swarms 7 and 8 or Swarms 22, 23 and 24 (Type 2) were due to a large extent to the differences in the maturity stage composition of the swarms (Tables $2 \& 5$, Fig. 4) because the size of particular maturity stages was similar in each swarm.

\section{Relationship between length of maturity stages in a swarm}

Not only does the size of each maturity stage vary between swarms, but in some swarms it appears that the mean length of each maturity stage may be longer than the population average while in other swarms they may be shorter than average. For example, in Swarms $15,29,36,47,50$ and 57 the mean length of krill in each maturity stage was greater than the population mean length for that maturity stage (Table 5). Similarly in Swarm 16 the mean length of each maturity stage was smaller than average. However, when considering all swarms, the significant interaction term $(0.05>p>0.01)$ between swarm and the linear trend of increasing krill size with increasing maturity is taken to indicate that in general the mean lengths of the maturity stages in a swarm did not all deviate in the same direction from the population mean sizes for the maturity stages.

\section{Krill size and the association of maturity stages}

In an earlier section we have shown that the occurrence of some maturity stages in a swarm was correlated (Tables 3 \& 4), while these associated stages were of a similar maturity they were not necessarily a similar size. There was no correlation ( $r=0.175 ; \mathrm{p} \gg 0.1)$ between the size difference of each maturity stage (taken from Table 5) and the degree of association between maturity stages (taken from Tables 3 \& 4). Thus, for example, subadult male krill (MS1, MS2, MS3) were usually found together but the mean sizes of these stages ranged from 42.8 to $48.4 \mathrm{~mm}$. In contrast, subadult male krill (MS3) and adult male krill (MA2) were seldom found together but the difference between the mean length of these stages was only $0.1 \mathrm{~mm}$.

\section{Range of krill sizes in swarms}

In addition to differences in the mean length of krill in swarms, the overall range of sizes of krill in each swarm may be quite variable (Table 2 ). Here we define the size range of a swarm as the difference between the longest and shortest krill in the swarm. The smallest size range was $11 \mathrm{~mm}$ (Swarms 8 and 57) while the largest was $30 \mathrm{~mm}$ (Swarm 40) and the median range was $15 \mathrm{~mm}$. Two swarms may have the same mean length (Table 5) but the size range of krill may be quite different; compare for instance Swarms 16 and 40 or Swarms 14 and 49 (Table 2).

The number of krill measured in a sample varied, so a small size range could be due to the reduced chance of encountering the less frequent long or short krill in small samples. Note, however, that while Swarm 8, with the smallest size range, came from the smallest sample, other swarms with small size ranges $(11$ to $12 \mathrm{~mm}$ ) came from samples containing over $100 \mathrm{krill}$ (Swarms 19, 32, 57). Conversely a large size range could be due to our inability, on occasion, to sample discrete swarms with the LLHPR; thus 2 swarms with small but different sizes ranges could be mixed together in a single sample. Indeed for 3 of the 4 samples with the greatest size ranges (Swarms 28, 40, 49) several compact swarms occurring close together were identified on the echo-chart. However, further examination of the echo-charts showed that samples with small size ranges came from all sizes of swarms and not just small, compact swarms.

There was no obvious relationship between sex ratio and size range of krill in a swarm. However, no swarms containing krill of just one sex but with a large size range were sampled (Fig. 5). Because of the size differences between maturity stages it might be expected that swarms with a restricted size range of krill (i.e. range smaller than the median value) would contain

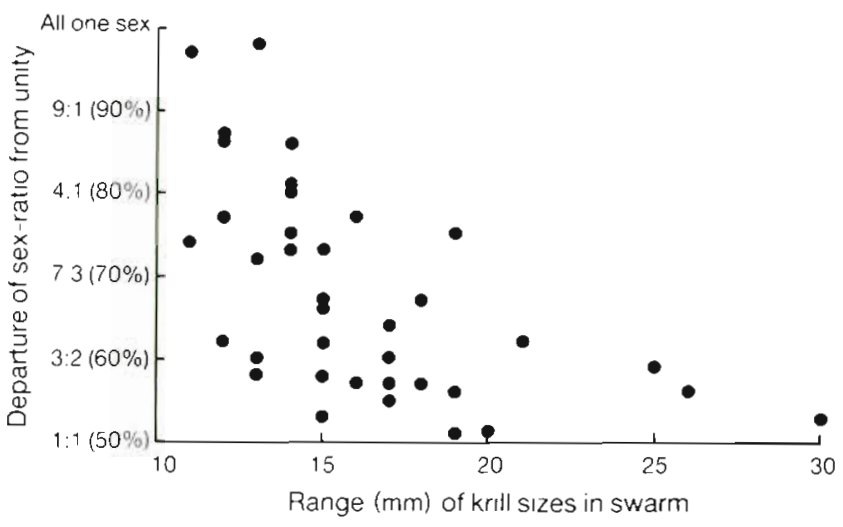

Fig. 5. Euphausia superba. Relationship between sex ratio and range of krill sizes in a swarm 
only a few maturity stages (e.g. Swarms 8 and 58). However, some of those swarms that contained a wide range of maturity stages still had a small size range (e.g. Swarm 32). In these swarms the less mature stages tended to be longer than average while the more mature stages tended to be shorter than average thus compressing the size range of the swarm.

\section{Comparison with size range of krill in swarms generated by randomization}

To help assess whether the range of krill sizes in these naturally occurring swarms might arise purely by chance, we compared the distribution of size ranges from the field data with swarms generated by randomization. There was a significant shift in the distribution of the size range towards smaller ranges in the naturally occurring swarms when compared with the size range of krill in the random swarms (KolmogorovSmirnov test, $p<0.001$; Fig. 6). However, there were also more naturally occurring swarms with large size ranges than expected, this may be partly due to the inability to separate swarms that occurred very close together (see above).

\section{DISCUSSION}

\section{Maturity-stage composition}

In a considerable number of studies and surveys, details of size, sex ratio and maturity stage of Euphausia superba over relatively large scales show the large variation in these characteristics (e.g. Witek et al. 1981, Fevolden \& George 1984, Siegel 1986). The data pre-

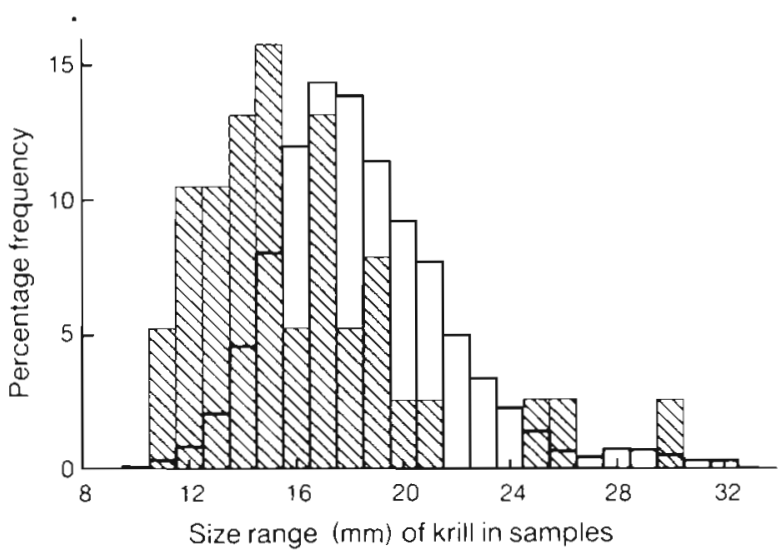

Fig. 6. Euphausia superba. Distribution of size range of krill in swarms observed in field (hatched bars) and of krill swarms generated by computer randomization from the overall field population (open bars with heavy outline) sented in this paper illustrate the great variation, in terms of the maturity-stage composition, of samples taken from swarms in a restricted area (see also Watkins 1986, Watkins et al. 1986). This variation between the reproductive status of swarms is expressed through changes in sex ratio, changes in maturity and also in the sizes of each maturity stage. Extreme variations in sex ratio have been noted in a number of studies (e.g. Marr 1962, Mauchline \& Fisher 1969, Mauchline 1980, Quetin \& Ross 1984) Marr (1962) found that whilst the sex ratio of most samples did not depart significantly from $1: 1,10 \%$ of the samples had a sex ratio more extreme than $1: 3$. In contrast such extreme sex ratios were found in over one quarter of the swarms sampled in this study. Similar extreme sex ratios are not, however, unusual in surface swarms of E. superba (Nemoto et al. 1981). In surface swarms of Meganyctiphanes norvegica extreme sex ratios were observed frequently by Nicol (1984) but all the swarms caught in one year were male dominated and in another year were female dominated. However, extreme sex ratios did not occur regularly in the surface swarms of Nyctiphanes australis observed by O'Brien (1988). In the present study, although the sex ratio in individual sub-surface swarms was extremely variable, the sex ratio in the overall population was close to $1: 1$ (53\% male).

In larger scale studies, different maturity stages may be spatially distinct, for instance on the west side of the Antarctic Peninsula juveniles occur nearer inshore than adults and mature krill (Quetin \& Ross 1984 Siegel 1986). In this study, while few juveniles were found, there was little spatial separation between swarms containing mainly adults and swarms containing mainly subadults.

\section{Potential causes for observed variation between swarms}

While large inter-swarm variations have been observed in many studies, there has been less consensus on the mechanisms by which such variation may arise. Krill are highly mobile, fast swimming Crustaceans (Kils 1983) and frequently exhibit a pronounced aggregation behaviour that at times may produce swarm densities as high as $30000 \mathrm{krill} \mathrm{m}^{-3}$ (Hamner et al. 1983). Swarms are often found at different depths through a diurnal cycle, with krill occurring near or at the surface at night (Nast 1979, Witek et al. 1981); in addition the swarms may disperse at night (Kalinowski 1978, Everson 1982). The organization of krill within a swarm may also be quite regular with parallel orientation and even spacing between individuals (Hamner et al. 1983). The restricted size range of krill in the 
swarm compared to that in the general population has led to the conclusion that some kind of lengthdependent sorting mechanism was responsible for the observed swarm composition (Mauchline 1980, Kils 1981, Hamner et al. 1983).

Here we consider some possible selective processes that may be contributing to the observed patterns of maturity-stage distribution. These processes have been split into 2 groups: (1) passive processes, for instance as a result of the physical characteristics of the krill (such as size producing size-dependent swimming or sinking ) or due to interactions with the environment; (2) active processes such as social behaviour that would imply some sort of choice by the krill.

\section{Passive processes}

It has been suggested that changes in sex ratio within a euphausiid population over a period of time arise from differential mortality associated with spermatophore transfer and egg laying (Mauchline 1980, discussed in detail in Nicol 1984). To obtain the extreme sex ratios seen in this study from a swarm having the population sex ratio as many as half the krill in some swarms would have to die. Such a degree of mortality would have a marked effect on population dynamics of a species that not only spawns over several years (e.g. Siegel 1987) but may also spawn several times within a single year (Ross \& Quetin 1983). It is therefore unlikely that sex ratio variation at the swarm level is due to mortality of post-spawning individuals.

Variation in maturity stage composition of the swarms could arise due to the size differences between maturity stages. It has been proposed that the size range of krill in a swarm may be restricted because of a length-dependent sorting mechanism based on swimming speeds (Mauchline 1980, Hamner et al. 1983) or sinking speeds (Kils 1981) and integrated models of swarm formation and maintenance based on feeding and swimming have been proposed (Antezana $\&$ Ray 1983). Indeed in this study the size range of krill in a swarm was less than that expected if swarms arose by a purely random process, which may be taken to indicate a length-based sorting mechanism. However, in general the size range of krill within a swarm (i.e. the difference between the smallest and the largest krill) was large (13 to $30 \mathrm{~mm}$ ) compared to the differences in the mean length of krill in the swarms (differences between swarms in a haul were less than $4 \mathrm{~mm}$ ). Therefore, although the size distributions of the swarms were statistically different, there was still considerable overlap in the size of krill in different swarms. While a length-based sorting mechanism would adequately explain differences between swarms of juveniles and adults as suggested for instance by Quetin \& Ross (1984), it seems unlikely that differences in sex and maturity stage composition of the swarms in this study could be explained simply by the size differences in the maturity stages. In general, krill of similar maturity tended to occur together in the same swarms but the size of these stages was often quite different. It is difficult to explain differences in sex ratio on the basis of length because the size differences between the equivalent male and female maturity stages (e.g. MA2 and FA4) were usually small (although sometimes statistically significant). Unfortunately it is not known how much of an effect the differing body shape of gravid females (with a swollen carapace) and mature males may have had on swimming speeds.

Size differences in maturity stages in the different swarms may have occurred as a result of the different environmental conditions that these swarms encountered. If different amounts of food were available to separate swarms over the period of a moult cycle then this would be reflected in differential growth. Reliable information on growth rate in the field is scarce but if we use the maximum and minimum growth rates observed in a laboratory study by Morris \& Keck (1984) then in one intermoult period (ca 14 d) the difference in the size of krill in swarms growing at the maximum $\left(0.171 \mathrm{~mm} \mathrm{~d}^{-1}\right)$ and minimum $\left(0.023 \mathrm{~mm} \mathrm{~d}^{-1}\right)$ values will be around $2 \mathrm{~mm}$. In the case of the 'Discovery' data re-analysed by Rosenberg et al. (1986), summer growth rates of 0.105 and $0.179 \mathrm{~mm} \mathrm{~d}^{-1}$ would produce size differences of more than $1 \mathrm{~mm}$ in an intermoult period. For this effect to be noticeable 2 conditions need to be satisfied: (1) individual swarms must remain coherent and separate for at least several weeks; (2) food supply must be sufficiently patchy so that some swarms never encounter sufficient food to attain maximum growth rates. While there are a limited number of observations on the coherence of very large swarms (aggregations) of krill (e.g. Kanda et al. 1982, Macaulay et al. 1984) such observations give no idea of the coherence and integrity of small, individual swarms of the type found in this study. In this study it is likely that mixing of adjacent swarms was not as frequent as in some other areas (see for instance Kalinowski 1978, Everson 1982 ) as no obvious night time dispersion was observed. At times a number of extensive krill layers were observed but the majority of the swarms generally did not disperse to any great extent nor did they migrate to the surface at night (Watkins et al. 1986), so mixing on a large scale is unlikely to have occurred on a daily basis. However, while Priddle et al. (1990) show that there was a large degree of variation in the digestive tract fluorescence of krill both within and between 
swarms, it is likely that the variation described is too local for such growth differences to have arisen here. Therefore, it seems unlikely that swarms in which krill of each maturity stage were larger than average and other swarms with maturity stages that were all smaller than average could have occurred because these swarms had been together for several weeks and so growth differences between the swarms were becoming apparent.

\section{Active processes}

The above mechanisms that allow the sorting of krill in swarms to arise passively as a result of the physical characteristics of the krill do not appear to account for all the variation in sex ratio and maturity observed in this study. It is likely, therefore, that krill have active behavioural responses that affect the sex ratio or maturitystage composition. According to Downes (1969), males in insect swarms predominate because the females drop out of the swarm after mating. Terazaki (1981; cited in Endo et al. 1986) saw that copulated females of Euphausia pacifica had a distinct behavioural pattern. Thus in this study the presence of swarms that are almost exclusively mature males may also be due to segregation due to active reproductive behaviour. Association between krill of similar maturity stages could be due to behavioural responses to chemical attractants (the role of chemical cues was reviewed by Carr 1988). Although there is no work on sex pheromones in krill, Hamner et al. (1983) have demonstrated that E. superba feeds in response to chemical cues.

\section{Implications for reproductive success}

The population that these swarms came from can be considered to be reproductively active: the majority of the krill were adult and nearly $30 \%$ were mature males carrying spermatophores. For krill to be reproductively successful mature males and females must come together so that spermatophore transfer can take place. Spermatophore transfer must be performed a number of times prior to spawning because attached spermatophores are lost when female krill moult (Buchholz et al. unpubl.). Therefore it would appear advantageous for female krill of maturity stages FA2 to FA4 to associate with mature males (MA1 and MA2). Despite the wide range of sex ratios in swarms, nearly all females from FA2 onwards had attached spermatophores, so mating occurred rapidly after each moult. Although there is no information on the rate or metabolic cost of spermatophore production, FA3 and FA4 krill were moulting every 2 wk (Buchholz et al. un- publ.) so, in female dominated swarms, each male would need to produce at least 2 spermatophores $w^{-1}$. However, although there was no direct evidence of diurnal mixing through nocturnal swarm dispersion (Ricketts et al. 1992), the rate at which swarms encounter each other and exchange individuals will also be important in determining how frequently spermatophores can be transfered. Such encounter rates may be increased by the presence of swarms containing only mature males which actively seek females. Thus the cost of reproduction for male krill may also include a significant expenditure on searching as well as producing spermatophores.

\section{CONCLUSIONS}

This study reveals great variation in the composition of krill swarms in terms of the sex, maturity and length of krill. Swarms may: (1) comprise an equal mixture of male and female krill or may contain just one sex; (2) contain mainly adults or mainly immature krill; (3) contain similar maturity stages of quite different sizes occurring together; (4) comprise maturity stages that are all larger than the population average (or smaller than average); (5) have a restricted size range. It is probable that size-dependent sorting, differential growth in response to food supply and active behavioural responses all influence the observed composition of the krill swarms. Many of the questions about how and why krill swarms form and maintain their structure will only be answered when the behaviour of individual swarms have been observed over a period of time. New hypotheses to explain swarm formation and maintenance must take account not only of the length of the krill but also both sex and maturity stage of the component krill.

Acknowledgements. We thank officers and crew of RRS 'John Biscoe' and the OBP team for help in collecting samples. $\mathrm{S}$. Cook assisted with the measurement of krill in Cambridge. We especially thank A. W. A. Murray for help with the ANOVA.

\section{LITERATURE CITED}

Anonymous (1988). MINITAB statistical software. Reference manual release 6.1. PWS Publishers, Boston

Antezana, T., Ray, K. (1983). Aggregation of Euphausia superba as an adaptive group strategy to the Antarctic ecosystem. In: Schnack, S. B. (ed.) On the biology of krill Euphausia superba. Proceedings of the seminar and report of the krill ecology working group. Ber Polarforsch, (Bremerhaven) (Sdhft) 4: 199-215

Bone, D. G. (1986). An LLHPR system for adult Antarctic krill (Euphausia superba). Br. Antarct. Surv. Bull. 73: 955-960 
Carr, W. E.S. (1988). The molecular nature of chemical stimuli in the aquatic environment. In: Atema, J., Fay, R. R., Popper, A. N., Travolga, W. N. (eds.) Sensory biology in the aquatic environment. Springer-Verlag, New York, p. $3-27$

Downes, J. (1969). The swarming and mating flight of Diptera. A. Rev. Ent. 14:271-298

Eddie, G. O. (1977). The harvesting of krill. FAO Rep. GLO/SO/77/2 Southern Ocean Fisheries Research Programme, Rome

Endo, Y. (1984). Daytime surface swarming of Euphausia pacifica (Crustacea: Euphausiacea) in the Sanriku coastal waters off northeastern Japan. Mar. Biol. 79: 269-276

Endo, Y., Imaseki, T., Komaki, Y (1986). Biomass and population structure of Antarctic krill (Euphausia superba Dana) collected during SIBEX II cruise of R.V. Kaiyo Maru. Mem. natn. Inst. polar Res., Tokyo (Spec. Issue) 44: 107-117

Everson, I (1982). Diurnal variation in mean volume backscattering strength of an Antarctic krill (Euphausia superbaj patch. J. Plankton Res. 4: 155-162

Fevolden, S. E., George, R. Y (1984). Size frequency pattern of Euphausia superba in the Antarctic Peninsula waters in the austral summer of 1983. J. Crustacean Biol. 4 (Spec. 1): $107-122$

Hamner, W. M., Hamner, P. P., Strand, S. W., Gilmer, R. W. (1983). Behavior of Antarctic krill, Euphausia superba: chemoreception, feeding, schooling, and molting. Science 220: $443-435$

Hamner, W. M. (1984). Aspects of schooling in Euphausia superba. J. Crustacean Biol. 4(Spec. 1): $67-74$

Kalinowski, J. (1978). Vertical migration of krill in the region of South Georgia, February-March 1976. Pol. Arch Hydrobiol. 25: 573-583

Kalinowski, J., Witek, Z. (1985). Scheme for classifying aggregations of Antarctic krill. BIOMASS Handb. Ser. 27

Kanda, K., Takagi, K., Seki, Y (1982). Movement of the larger swarms of Antarctic krill Euphausia superba population off Enderby Land during 1976-1977 season. J. Tokyo Univ. Fish. 68: 25-42

Kils, U. (1981). Size dissociation in krill swarms. Kieler Meeresforsch. 5: 262-263

Kils, U. (1983). Swimming and feeding of Antarctic krill, Euphausia superba-some outstanding energetics and dynamics - some unique morphological details. In: Schnack S.B. (ed.) On the biology of krill Euphausia superba. Proceedings of the seminar and report of the krill ecology working group. Ber. Polarforsch. (Bremerhaven) (Sdhft) 4 : $131-155$

Macaulay, M. C., English, T S., Mathisen, O. A. (1984). Acoustic characterization of swarms of Antarctic krill (Euphausia superba) from Elephant Island and Bransfield Strait. J. Crustacean Biol. 4 (Spec. 1): 16-44

Makarov, R. R., Denys, C. J. (1981). Stages of sexual maturity of Euphausia superba Dana. BIOMASS Handb. Ser. 11

Marr, J. W. S. (1962). The natural history and geography of the Antarctic krill (Euphausia superba). 'Discovery' Rep. 32: $33-464$

Mauchline, J. (1980). The biology of mysids and euphausiids Adv. mar. Biol. 18: 1-681

Mauchline, J., Fisher, L. R. (1969). The biology of euphausiids Adv. mar. Biol. 7: 1-454

Miller, D., Hampton, I. (1989). Biology and ecology of the Antarctic krill (Euphausia superba Dana): a review. BIOMASS scient. Ser. 9. SCAR, Cambridge

Morris, D. J., Keck, A. (1984). The time course of the moult cycle and growth of Euphausia superba in the laboratory. Meeresforsch. 30:94-100

This article was presented by J. Mauchline, Oban, Argyll, Scotland
Morris, D. J., Watkins, J. L. (1986). Krill swarms: does proximity imply similarity. BIOMASS Newsl. 8(1): 6-7

Morris, D. J., Watkins, J. L., Ricketts, C., Buchholz, F., Priddle, J. (1988). An assessment of the merits of length and weight measurements of Antarctic krill Euphausia superba. Br. Antarct. Surv. Bull. 79: 27-50

Murphy, E. J., Morris, D. J., Watkins, J. L., Priddle, J. (1988). Scales of interaction between Antarctic krill and the environment. In: Sahrhage, D. (ed.) Antarctic Ocean and resources variability. Springer-Verlag, Berlin, p. 120-130

Nast, F. (1979). The vertical distribution of larval and adut krill (Euphausia superba Dana) on a time station south of Elephant Island, South Shetlands. Meersforsch. 27: $103-118$

Nemoto, T., Doi, T., Nasu, K. (1981). Biological characteristics of krill caught in the Southern Ocean. In: Biomass, Vol II, Selected contributions to the Woods Hole Conterence on living resources of the Southern Ocean, 1976. SCAR, Cambridge, p. $47-64$

Nicol, S. (1984). Population structure of daytime surface swarms of the euphausid Meganyctiphanes norvegica in the Bay of Fundy. Mar. Ecol. Prog. Ser. 18: 241-251

O'Brien, D. P. (1988). Surface schooling behaviour of the coastal krill Nyctiphanes australis (Crustacea: Euphausiacea). Mar. Ecol. Prog. Ser. 42: 219-233

Payne, R. W. Lane, P. W., Ainsley, A. E., Bicknell, K. E., Digby, P. G. N., Gower, J. C., Harding, S. A., Leech, P. K., Simpson, H. R., Todd, A. D., Verrier, P. J., White, R. P., Tunnicliffe Wilson, G., Paterson, L. J. (1987). GENSTAT 5 Reference Manual. Oxford University Press, Oxford

Quetin, L. B., Ross, R. M. (1984). School composition of the Antarctic krill Euphausia superba in waters west of the Antarctic Peninsula in the austral summer of 1982. J. Crustacean Biol. 4 (Spec. 1): 96-106

Priddle, J., Watkins, J. L., Morris, D. J., Ricketts, C., Buchholz. F. (1990). Variation of feeding by krill in swarms. J. Plankton Res. 12: 1189-1205

Ricketts, C., Watkins, J. L., Priddle, J., Morris, D. J., Buchholz, F. (1992). An assessment of the biological and acoustic characteristics of swarms of Antarctic krill. Deep Sea Res. 39:359-371

Rosenberg, A. A., Beddington, J. R., Basson, M. (1986). The growth and longevity of krill during the first decade of pelagic whaling. Nature, Lond. 324: $152-154$

Ross, R. M., Quetin, L. B. (1983). Spawning frequency and fecundity of the Antarctic krill Euphausia superba. Mar. Biol. 77: 201-205

Siegel, V. (1986). Structure and composition of the Antarctic krill stock in the Bransfield Strait (Antarctic peninsula) during the Second International BIOMASS Experiment (SiBEX). Arch. FischWiss. 37 (Beih. 1): 51-72

Siegel, V. (1987). Age and growth of Antarctic Euphausiacea (Crustacea) under natural conditions. Mar Biol. 96 : $483-495$

Watkins, J. L. (1986). Variations in the size of Antarctic krill, Euphausia superba Dana, in small swarms. Mar. Ecol. Prog. Ser. 31:67-73

Watkins, J. L., Morris, D. J., Ricketts, C., Priddle, J. (1986). Difterences between swarms of Antarctic krill and some implications for sampling krill populations. Mar. Biol. 93: $137-146$

Watkins, J. L., Morris, D. J., Ricketts, C., Murray, A. W. A. (1990). Sampling biological characteristics of krill: effect of heterogeneous nature of swarms. Mar. Biol. 107: 409-415

Witek, Z., Kalinowski, J., Grelowski, A., Wolnomiejski, N. (1981). Studies of aggregations of krill (Euphausia superba). Meeresforsch. 28: 228-243

Manuscript first received: January 21, 1992

Revised version accepted: March 27, 1992 